\title{
Impact of continuous quality improvement on selection of pacing mode and rate of complications in permanent pacing
}

\author{
J E Møller, E H Simonsen, M Møller
}

\begin{abstract}
Objective-To improve pacing mode selection and to reduce complications of pacing using continuous quality improvement.

Design-Criterion standard study. Comparison of implantations from 1992-94 with preset standards. Implementation of corrections in 1994 and re-evaluation in 1995, with one year follow up of all patients.

Setting-Tertiary hospital.

Patients-Consecutive patients implanted with a pacemaker from January 1992 to October 1993, 361 patients; October 1993 to June 1994, 115 patients; and January 1995 to October 1995, 140 patients.

Main outcome measures-Reasons for not choosing physiological pacing and complications of pacemaker implantation.
\end{abstract}

Results-Most frequent reasons for not selecting physiological pacing for patients in sinus node disease were age $(12 \cdot 8 \%, 5$ of 39) and technical problems $(12 \cdot 8 \%, 5$ of 39); and for patients in atrioventricular block, age (31.4\%, 16 of 51), and disability due to other diseases $(13.7 \%, 7$ of 51$)$. To improve the standards, age as a sole reason for not selecting physiological pacing was disregarded and VDD pacing was introduced. Follow up showed fulfilment of standards. Cost analysis indicated minimally increased expenses of pacing hardware and no additional costs of procedures. A high rate of complications $(16 \cdot 2 \%, 77$ of 476$)$ was found related to atrial lead displacement $(10.2 \%, 19$ of 186), and to subclavian puncture from January 92-June 94. To reduce complications use of atrial screw-in leads and cephalic cut down were encouraged. Follow up showed significant reduction of complications from January 92-June 94 (77 of 476) compared with January 95-October 95 (12 of 140) ( $P=0 \cdot 03)$.

Conclusion-Better compliance with international pacing guidelines was obtained by registration of reasons for deviations followed by corrections of procedures. By using screw-in leads and by using cephalic cut down the set standards were met.

(Heart 1997;77:357-362)
Keywords: continuous quality improvement; complications of permanent pacing; dual chamber pacing; single chamber pacing

The present study describes how continuous quality improvement influenced the selection of pacing mode and rate of early complications after pacemaker implantation at Odense University Hospital in Denmark. Pacemaker implants have been performed at the hospital since 1963 and about 200 primary pacemaker implants are performed annually. The Danish Pacemaker Register is situated at Odense University Hospital. This register encompasses all active implants performed in Denmark since 1982 (100\% registration), data on generators and leads are available on more than 18000 patients.

\section{Methods}

Continuous quality improvement was by: (a) definition of criteria and standards; (b) data collection on current performance; (c) assessment of performance against the criteria and standards; (d) implementation of changes; (e) re-evaluation of current performance to assess improvements.

Specific standards were set in 1993 for selection of pacing mode and for acceptable rates of early complications. Standards for selection of pacing mode were based on the British Pacing and Electrophysiology Group guidelines (table 1). ${ }^{1}$ Standards and definitions for early complications were based on earlier reports on the subject (table 2).$^{2-4}$

We prospectively collected data on 115 consecutive patients from October 1993-June 1994. At time of implant the following recordings were made: demographic data, indication for pacing, mode of pacing, and operator's reason if mode differed from guidelines in table 1. Pacing hardware used, operator, venous access, duration of operation and of fluoroscopy, and inpatient bed days were also recorded. In the follow up period of one year we recorded duration of first outpatient attendance, complications, reprogramming, and

Table 1 Guidelines for selection of pacing mode ${ }^{I}$

1 The ventricle should be paced if there is actual or threatening atrioventricular block

2 The atrium should be paced/sensed unless contraindicated 3 Atrial pacing/sensing is contraindicated by the presence of chronic atrial flutter or fibrillation 
Table 2 Standards and definitions of early complications ${ }^{2-4}$

\begin{tabular}{|c|c|c|c|}
\hline Complication & Definition & Standard & \\
\hline Overall & $\begin{array}{l}\text { Any event that required surgical } \\
\text { intervention in the first } 12 \text { months } \\
\text { after implantation of permanent pacemaker }\end{array}$ & $5 \%$ & \\
\hline Lead displacement & $\begin{array}{l}\text { Visible change of lead tip's position on } \\
\text { chest } x \text { ray or a threshold rise as detected } \\
\text { by a failure to capture at maximal output }\end{array}$ & $\begin{array}{l}\text { Atrial } \\
\text { Ventricular }\end{array}$ & $\begin{array}{l}5 \% \\
2 \%\end{array}$ \\
\hline Pneumothorax & Air in the pleural cavity requiring drainage & $2 \%$ & \\
\hline Haematoma & $\begin{array}{l}\text { Swelling of the generator pocket requiring surgery } \\
\text { for haemostasis }\end{array}$ & $1 \%$ & \\
\hline Infection & $\begin{array}{l}1 \text { Local inflammation or abscess formation in the } \\
\text { generator pocket } \\
2 \text { Erosion of part of the pacing system through } \\
\text { the skin with secondary infection } \\
3 \text { Fever and positive blood cultures in a patient } \\
\text { without focus of infection elsewhere }\end{array}$ & $0.5 \%$ & \\
\hline
\end{tabular}

number of outpatient attendances. The cost of pacing hardware was assessed using an arbitrary currency unit based on the cost of a single chamber generator and one lead being 100 units of currency. Using this arbitrary currency the cost for a dual chamber generator and two leads was 141 units, and for a VDD system it was 111 units.

Preliminary evaluation of these data showed a high rate of early complications. To evaluate the magnitude of the problem, further data were collected in a retrospective manner on 361 consecutive patients having a primary pacemaker implant from January 1992October 1993. Based on the results from both periods (January 1992-June 1994; 476 patients) a quality assessment was made and corrections were implemented.

Following this implementation a new prospective data collection was performed from January 1995-October 1995 in 140 consecutive patients.

\section{STATISTICAL ANALYSIS}

Complication rates and mode of pacing were tested against standards using one tailed binomial test with continuity correction. Proportions were tested using the $\chi^{2}$ test with Yates's correction when appropriate. Significance was defined as $\mathrm{P}<0.05$.

\section{Results}

PATIENTS AND INDICATIONS FOR PACING

fanuary 1992-October 1993 A total of 371 patients had a primary pacemaker implant and complete data were available for 361 patients $(97 \cdot 3 \%)$

October 1993-fune 1994 A total of 115 patients had a primary pacemaker implant and data for all patients were available.

fanuary 1995-October 1995 A total of 140 patients had a primary pacemaker implant data for all patients were available.

Demographic data and indications for permanent pacing in all three periods are listed in table 3.

SELECTION OF PACING MODE

Mode of pacing in the three periods is presented in the figure, and fulfilment of standards and reasons for not following standards are summarised in table 4 .

The most frequent reason stated for not selecting a physiological pacing mode during October 1993-June 1994 for patients with atrioventricular block was age. The median age in this group meeting the guidelines was 75 years (range 21 to 91 ) compared with 82 years (75 to 94) in the group not meeting the guidelines. A similar difference was found for the period January 1995-October 1995; median age 72 years (range 7 to 93 ) and 86 years ( 81 to 94$)$, respectively. The frequency of stating patient age as a reason for not selecting a physiological pacing mode was lower in the January 1995-October 1995 group (8 of 140 patients, $5.7 \%$ ) than in the October 1993-June 1994 group (21 of 115 patients, $18.3 \%)$. In the October 1993-June 1994 group, inexperienced operators (residents in training) selected a ventricular single chamber pacemaker for 38 of 69 patients $(55 \cdot 1 \%)$ while experienced operators selected this pacing mode for 14 of 46 patients $(30 \cdot 4 \%)$.

\section{COST ASSESSMENT}

Table 5 summarises costs of pacing hardware, duration of procedures, mean inpatient bed days, follow up, and hospitalisation due to pacemaker related problems.

October 1993-Fune 94 Mean duration of implantation was 58 minutes for a ventricular single chamber pacemaker, 75 minutes for an atrial single chamber pacemaker, and $82 \mathrm{~min}$ utes for a dual chamber pacemaker.

fanuary 1995-October 1995 Mean duration of implantation was 55 minutes for a ventricular single chamber pacemaker, 79 minutes for an atrial single chamber pacemaker, 67 minutes for a VDD pacemaker, and 85 minutes for a dual chamber pacemaker.

October 1993-Fune 1994 No difference in duration of outpatient attendance was identified for physiological pacing compared with ventricular single chamber pacing (25 $v 23 \mathrm{~min}-$ utes, $P=0 \cdot 25$ ).

The mean cost of pacing hardware for all indications rose from 112 to 114 units $(1 \cdot 8 \%)$

Table 3 Demographic patient data and indications for pacing

\begin{tabular}{llll}
\hline & fanuary 92-October 93 & October 93-fune 94 & fanuary-October 95 \\
\hline Age (years) median (range) & $76(6-93)$ & $77(21-94)$ & $76(7-95)$ \\
Mortality during one year follow up (n) & $11 \cdot 1 \%(40)$ & $10 \cdot 4 \%(12)$ & $10 \cdot 7 \%(15)$ \\
Sex (n): & $48 \%(174)$ & $43 \%(49)$ & $44 \%(62)$ \\
$\quad$ Female & $52 \%(187)$ & $57 \%(66)$ & $56 \%(78)$ \\
Male & $30 \%(107)$ & $24 \%(28)$ & $21 \%(30)$ \\
Indication for pacing (n): & $7 \%(24)$ & $10 \%(11)$ & $6 \%(9)$ \\
$\quad$ Sinus node disease & $46 \%(168)$ & $44 \%(51)$ & $41 \%(57)$ \\
Sinus node disease and atrioventricular block & $14 \%(50)$ & $16 \%(18)$ & $23 \%(32)$ \\
Atrioventricular block & $3 \%(12)$ & $6 \%(7)$ & $9 \%(12)$ \\
Atrial fibrillation and bradycardia & & & 9 \\
\hline
\end{tabular}


Pacing mode in patients paced for sinus node disease or atrioventricular block. $A A I$, atrial single chamber pacemaker; DDD, dual chamber pacemaker; VVI, ventricular single chamber pacemaker.
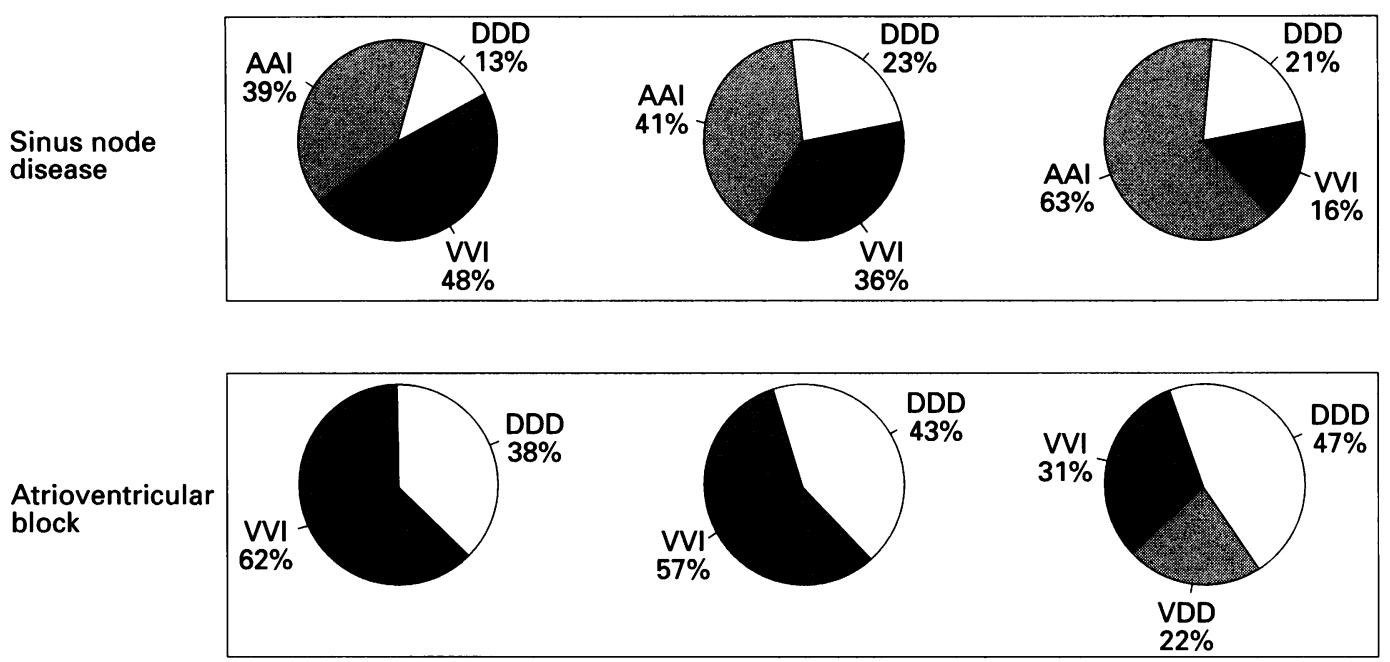

after implementation of changes, mostly related to increased expenses for patients with atrioventricular block. No difference in costs for patients with sinus node disease was identified (table 5).

\section{COMPLICATIONS}

It was decided to pool data regarding early complications for the period January 1992-June 1994 during which time there were 486 consecutive patients and data were available on $476(97 \cdot 9 \%)$. Complications were encountered in 77 patients $(16.2 \%$ ) (table 6), which was significantly higher $(P<0.001)$ than the standard (table 2). From January 1995-October 1995 complications were encountered in 12 of 140 patients $(8.6 \%)$ (table 6), which was not significantly higher than the standard $(P=0.09)$. The overall complication rate was significantly higher in January 1992-June 1994 compared with January 1995-October $1995(P=0.03)$.

\section{Leads and displacement}

Fanuary 1992-fune 1994 Of the 186 atrial leads used $71 \%$ were tined unipolar leads, $2 \cdot 1 \%$ were unipolar screw-in leads, and $26.9 \%$ were tined bipolar leads; of the 407 ventricular leads $90 \cdot 2 \%$ were bipolar tined and $9 \cdot 8 \%$ were tined unipolar leads. Atrial lead displacement occurred in 19 patients $(10.2 \%)$ and ventricular lead displacement in six patients $(1.5 \%)$ $(P<0.001)$. Standards for lead displacement were met for ventricular but not for atrial leads.

Table 4 Fulfilment of guidelines for selection of pacing mode and reasons for not meeting guidelines

\begin{tabular}{|c|c|c|c|c|c|c|}
\hline & \multicolumn{3}{|c|}{ Sinus node disease } & \multicolumn{3}{|c|}{ Atrioventricular block } \\
\hline & $\begin{array}{l}\text { Fanuary 92- } \\
\text { October } 93\end{array}$ & $\begin{array}{l}\text { October 93- } \\
\text { fune } 94\end{array}$ & $\begin{array}{l}\text { Fanuary 95- } \\
\text { October } 95\end{array}$ & $\begin{array}{l}\text { Fanuary 92- } \\
\text { October } 93\end{array}$ & $\begin{array}{l}\text { October 93- } \\
\text { fune } 94\end{array}$ & $\begin{array}{l}\text { Fanuary 95- } \\
\text { October } 95\end{array}$ \\
\hline \multirow{3}{*}{$\begin{array}{l}\text { Maintaining atrioventricular } \\
\text { syncrony (n) } \\
\text { Reason for not maintaining } \\
\text { atrioventricular syncrony (n): } \\
\text { Age of patient } \\
\text { Disabled by another disease } \\
\text { Short life expectancy due to } \\
\text { another disease } \\
\text { Technical problems } \\
\text { Atrial fibrillation at implant }\end{array}$} & $51 \%(67)$ & $64 \%(25)^{\star}$ & $84 \%(33)^{\star}$ & $38 \%(64)$ & $43 \%(22)^{\star}$ & $70 \%(50)^{\star}$ \\
\hline & $\begin{array}{l}\text { NA } \\
\text { NA }\end{array}$ & $\begin{array}{r}12 \%(5) \\
3 \%(1)\end{array}$ & $\begin{array}{l}3 \%(1) \\
8 \%(3)\end{array}$ & $\begin{array}{l}\text { NA } \\
\text { NA }\end{array}$ & $\begin{array}{l}31 \%(16)^{\star} \\
14 \%(7)\end{array}$ & $\begin{array}{l}12 \%(7)^{\star} \\
7 \%(4)\end{array}$ \\
\hline & $\begin{array}{l}\text { NA } \\
\text { NA } \\
\text { NA }\end{array}$ & $\begin{array}{r}0 \%(0) \\
13 \%(5) \\
8 \%(3)\end{array}$ & $\begin{array}{l}0 \%(0) \\
5 \%(2) \\
0 \%(0)\end{array}$ & $\begin{array}{l}\text { NA } \\
\text { NA } \\
\text { NA }\end{array}$ & $\begin{array}{l}4 \%(2) \\
4 \%(2) \\
4 \%(2)\end{array}$ & $\begin{array}{l}5 \%(3) \\
5 \%(3) \\
0 \%(0)\end{array}$ \\
\hline
\end{tabular}

NA, Data not available.

$\star$ Significant difference between periods $(P<0.05)$.

Table 5 Cost of pacing hardware, duration of implantation and fluoroscopy, inpatient bed days, outpatient attendances, patients readmitted because of pacemaker related problems, and costs of extra hardware because of complications

\begin{tabular}{|c|c|c|c|c|}
\hline & \multicolumn{2}{|c|}{ Sinus node disease } & \multicolumn{2}{|c|}{ Atrioventricular block } \\
\hline & $\begin{array}{l}\text { October 93- } \\
\text { fune } 94\end{array}$ & $\begin{array}{l}\text { Fanuary 95- } \\
\text { October } 95\end{array}$ & $\begin{array}{l}\text { October 93- } \\
\text { fune } 94\end{array}$ & $\begin{array}{l}\text { Fanuary 95- } \\
\text { October } 95\end{array}$ \\
\hline \multirow{6}{*}{$\begin{array}{l}\text { Mean cost of hardware } \\
\text { Mean duration of operation } \\
\text { (min) (SD) } \\
\text { Mean duration of fluoroscopy } \\
\text { (min) (SD) } \\
\text { Mean inpatient bed days (SD) } \\
\text { Number of outpatient attendances, } \\
\text { median (range) } \\
\text { Readmitted because of pacemaker } \\
\text { problems } \\
\text { Cost of extra hardware because } \\
\text { complications (unitpatient) }\end{array}$} & 109 & 110 & 118 & 122 \\
\hline & $78(31)$ & $81(34)$ & $72(24)$ & 75 (32) \\
\hline & $\begin{array}{l}12(10) \\
3 \cdot 5(2 \cdot 8)\end{array}$ & $\begin{array}{l}12(7) \\
3.9(2.3)\end{array}$ & $\begin{array}{l}11(7) \\
3.8(3.0)\end{array}$ & $\begin{array}{l}14(11) \\
3.6(2 \cdot 2)\end{array}$ \\
\hline & $4(1-11)$ & $2(1-8)$ & $3(1-10)$ & $2(1-6)$ \\
\hline & $10 \cdot 2 \%(4 / 39)$ & $7 \cdot 8 \%(3 / 39)$ & $9 \cdot 8 \%(5 / 51)$ & $5 \cdot 2 \%(3 / 57)$ \\
\hline & 3.6 & 3.3 & $2 \cdot 0$ & 0 \\
\hline
\end{tabular}

^Arbitrary unit of currency based on the cost of a single chamber generator and one lead be set to 100 units of currency. 
Table 6 Complication rates

\begin{tabular}{lll}
\hline Complication & fanuary 92-fune 94 & fanuary 95-October 95 \\
\hline Overall (n) & $16 \cdot 2 \%(77)$ & $8 \cdot 6 \%(12)^{\star}$ \\
Displacement (n): & $10 \cdot 2 \%(19)$ & \\
$\quad$ Atrial & $1 \cdot 5 \%(6)$ & $1 \cdot 4 \%(1)^{\star}$ \\
$\quad$ Ventricular & $3 \cdot 2 \%(15)$ & $1 \cdot 8 \%(2)$ \\
Pneumothorax (n) & $1 \cdot 3 \%(6)$ & $1 \cdot 5 \%(2)$ \\
Haematoma (n) & $0 \cdot 6 \%(3)$ & $0 \%(0)$ \\
Infection (n) & $0 \cdot 7 \%(4)$ & $0 \cdot 5 \%(1)$ \\
Conductor fracture (n) & $5 \cdot 0 \%(24)$ & $2 \cdot 1 \%(3)$ \\
Other complications (n) &
\end{tabular}

^Significant difference between periods $(P<0.05)$.

Fanuary 1995-October 1995 Of the 70 atrial leads $90 \%$ were unipolar screw-in leads and $10 \%$ were unipolar tined leads; of the 114 ventricular leads $44.7 \%$ were tined unipolar, $43.9 \%$ were tined bipolar leads, and $11.4 \%$ were single pass leads with floating atrial dipole. Atrial lead displacement occurred in one patient $(1.4 \%)$ and ventricular lead displacement in two $(1.8 \%)$. Standards for ventricular and atrial lead displacement were met. During this period significantly fewer atrial lead displacements occurred compared with January 1992-June $1994(P=0.04)$, while the difference between ventricular lead displacement was not significant for the same two periods $(P=$ $0.98)$.

Other complications needing intervention

Pneumothorax requiring drainage From January 1992-June 1994, 15 patients (3.2\%) developed pneumothorax requiring drainage compared with two patients $(1.4 \%)$ from January 1995-October $1995(P=0 \cdot 42)$. In both periods standards were met.

Haematoma From January 1992-June 1994, six patients $(1.3 \%)$ developed haematoma in the pacemaker pocket needing surgical evacuation compared with three patients $(2 \cdot 1 \%)$ from January 1995-October 1995. In both periods standards were met.

Late infection From January 1992-June 1994, three patients $(0.6 \%)$ developed late infection requiring removal of the pacing system. No infections occurred from January 1995October 1995. All patients received prophylactic antibiotic treatment.

Other complications Local inconvenience from generator requiring reoperation, conductor fracture, intermittent exit block due to looping of the lead, thrombosis of the subclavian vein or accidental puncture of the subclavian artery associated with bleeding occurred in 24 patients $(5 \%)$ from January 92-June 94 and three patients $(2 \cdot 1 \%)$ from January 95October 95.

Deaths There were no deaths related to the surgical procedure during any of the time periods.

Mode of pacing

fanuary 1992-Fune 1994 Thirty eight of 184 patients $(20.6 \%)$ given a physiological pacemaker and 39 of $292(13.4 \%)$ given a ventricular single chamber pacemaker suffered complications $(P=0.04)$.

fanuary 1995-October 1995 Six of 84 patients $(7 \cdot 1 \%)$ given a physiological pacemaker and six of $56(10.7 \%)$ given a ventricular single chamber pacemaker suffered complications $(P=0 \cdot 30)$.
Venous access

Fanuary 1992-Fune 1994 Cephalic cut down was used as venous access for 301 of 593 leads $(50.8 \%)$, subclavian puncture for 289 $(48.7 \%)$, and external jugular vein for three $(0 \cdot 5 \%)$. A significantly higher rate of complications related to venous access (pneumothorax and haematoma) was found after subclavian puncture compared with cephalic cut down (19 of $289 v 0$ of 301, $\mathrm{P}<0.001$ ). No pneumothorax was seen after cephalic cut down while 15 were seen after subclavian punctures. Subclavian puncture was used in 77 of 119 patients $(64.7 \%)$ given a dual chamber pacemaker, and 116 of 292 patients $(39.7 \%)$ given a ventricular single chamber pacemaker.

fanuary 1995-October 1995 One hundred and sixteen of 184 leads $(63.0 \%)$ were implanted via the cephalic vein, while subclavian puncture was used for the remaining $68(37 \cdot 0 \%)$. The complication rate for the cephalic cut down group was $0.9 \%$ (1 of 116$)$ and $5.9 \%$ (4 of 68$)$ for the subclavian puncture group ( $P=$ $0 \cdot 12)$. Subclavian puncture was used for 17 of 44 patients $(38.6 \%)$ paced with dual chamber pacemaker, and for 22 of $57(38.6 \%)$ paced with single chamber ventricular pacemaker.

\section{Operators}

fanuary 1992-fune 1994 Seven residents in training implanted $51 \cdot 1 \%$ of the 476 pacemakers and $48.9 \%$ were implanted by two experienced cardiologists. No significant increase in complications was found for residents in training (42 of 243) compared with experienced operators (35 of 233) $(\mathrm{P}=0 \cdot 67)$.

Fanuary 1995-October 1995 Four residents in training implanted $79.3 \%$ of the 140 pacemakers and $20.7 \%$ were implanted by two experienced cardiologists. No significant increase in complications was found for residents in training ( 8 of 111) compared with experienced operators (4 of 29) $(P=0.45)$.

\section{Complications not requiring reoperation}

fanuary 1992-Fune 1994 Seven cases of atrial undersensing in 186 patients $(3.8 \%)$ and two cases of ventricular undersensing in 407 patients $(0.5 \%)$ were observed. Atrial undersensing was significantly more frequent than ventricular $(P=0.05)$. In 476 patients, five cases of diaphragmatic stimulation $(1 \cdot 1 \%)$ and two cases of oversensing $(0.4 \%)$ were seen. Pacemaker mediated tachycardia occurred in two of 119 patients $(1.7 \%)$ with dual chamber pacemaker implanted. All these complications were successfully treated by reprogramming. Pacemaker syndrome led to upgrading to a dual chamber system in 10 of 292 patients (3.1\%). One patient having an atrial single chamber system was upgraded to a dual chamber system due to atrioventricular block.

fanuary 1995-October 1995 One case of ventricular undersensing in 114 patients $(0.9 \%)$, one case of atrial undersensing in 70 patients $(1 \cdot 4 \%)$, and three cases of diaphragmatic stimulation in 140 patients $(2 \cdot 1 \%)$ were seen. Of the 58 patients with dual chamber pacing/ sensing, one $(1 \cdot 7 \%)$ suffered a pacemaker 
mediated tachycardia. All these complications were successfully treated by reprogramming.

One patient had an atrial single chamber system upgraded to dual chamber system due to atrioventricular block.

\section{Discussion}

MODE OF PACING

There is a general agreement on the advantages of atrial over ventricular pacing in sinus node disease. In a randomised trial, Andersen et $a l^{5}$ showed that atrial pacing was associated with lower frequencies of atrial fibrillation and thromboembolic complications compared with ventricular pacing, and a low risk of development of atrioventricular block; however, no difference in mortality was found. In a prospective but not randomised study, reduced mortality was found in atrial compared with ventricular pacing. ${ }^{6}$ Maintenance of atrioventricular synchrony in patients with atrioventricular block is associated with improvement of effort tolerance and subjective variables as breathlessness, palpitations and general well being. ${ }^{7-9}$ However, many patients still receive single chamber ventricular pacemakers, ${ }^{21011}$ probably due to the simplicity of implantation and follow up procedures of single lead ventricular systems, lower costs, ${ }^{811} 12$ and possibly a lower rate of complications. ${ }^{13}$

Our results indicate that selection of VVI mode in patients with atrioventricular block or sinus node disease was related to patient age, disability from another disease, atrial fibrillation at implant, and implantations performed by inexperienced operators. Cost of pacing hardware seemed an insignificant issue in the selection of pacing mode.

To improve the quality of pacing mode selection it was decided to disregard patient age as a reason for not selecting a physiological pacemaker, to use single pass lead VDD pacing in selected patients with normal function of the sinus node, to facilitate stable atrial lead position by use of screw-in leads, and to implant atrial leads in patients with intermittent atrial fibrillation at the time of implant. Follow up indicated an increased use of physiological pacing and a decrease in patients where age was the sole reason for not selecting the recommended pacing mode. The standards were met after implementations (table 1). Our results support the effect of internal audit on pacemaker prescription reported by Mounsey et al. ${ }^{12}$ In their study internal audit led to an increased use of atrial pacing in sinus node disease and an increase in dual chamber pacing for atrioventricular block. Our finding that experienced implanters are more likely to use complex pacemakers also supports earlier reports. $^{3}$

Registrations in the Danish Pacemaker Register showed an increased use of physiological pacing in Denmark from $47 \%$ in 1993 to $63 \%$ in 1995 . This general tendency to increased use of physiological pacing in Denmark has to be considered, when the improvements of mode selection found in our study are evaluated.
COST ASSESSMENT

Earlier reports ${ }^{11} 12$ have identified increased costs of pacing hardware as a consequence of increased use of physiological pacing, especially from increased costs for patients with atrioventricular block. In these studies VDD pacing were not used routinely. Our results indicated the improvement in selection of pacing mode was associated with less than $2 \%$ increase in costs of pacing hardware-without additional duration of procedures, complications or outpatient attendances. The use of VDD pacing in selected patients with atrioventricular block seemed to be a cost efficient way of adopting the guidelines for selection of pacing mode.

The present study suggests no estimate of long term costs. A recently published study by Sutton and Bourgeois ${ }^{14}$ indicates the long term costs of physiological pacing for sinus node disease and atrioventricular block to be less than the costs of ventricular single chamber pacing because of the reduced risk of long term complications (chronic atrial fibrillation, stroke, and congestive heart failure). This emphasising the benefits of physiological pacing.

\section{EARLY COMPLICATIONS}

An acceptable rate of early complications after pacemaker implantation was set to $5 \%$, according to the standard internationally accepted since $1974 .{ }^{15}$ After introduction of dual chamber and atrial pacing it has been debated whether this standard is still valid. Several authors did not observe any difference in complication rates comparing single and dual chamber pacemaker implantation, ${ }^{3416}$ while others found a higher frequency of complications for dual chamber pacing. ${ }^{13}$

During the period October 1993-July 1994 we found an unacceptably high rate of complications. To evaluate the magnitude of the problem, a retrospective registration was made for January 1992-October 1993. This was possible via the prospective registrations in the Danish Pacemaker Register, and the standard charts on all pacemaker patients at Odense University Hospital. All patients having a permanent pacemaker implanted had as a minimum the duration of their first outpatient attendance at the hospital recorded. The pooling of retrospective and prospective data was, therefore, considered acceptable in this case. A complication rate of $16 \cdot 2 \%$ was found for the period January 1992 June 1994. This was considerably higher than the set standard.

A significant higher rate of complications was seen after dual or atrial single chamber pacemaker implants compared with single chamber ventricular pacemaker implants, particularly in relation to atrial compared with ventricular lead displacement. A similar difference was reported by Chauhan et al,,$^{13}$ and Aggarwal et al,,$^{16}$ using tined atrial leads, although their displacement rates were substantially lower than ours. Other series showed no difference in atrial and ventricular lead displacement. In these series the majority of atrial leads were screw-in leads. ${ }^{3} 17$

For venous access the use of cephalic cut down has been recommended to avoid the vascular and pleural complications of subclavian 
puncture. ${ }^{18}$ However, no difference in complications related to venous access were found in earlier series. ${ }^{1316}$ In these series the majority of leads were placed using subclavian puncture. In our study a significantly higher rate of complications related to venous access was found when subclavian puncture was used rather than cephalic cut down. The results indicated the difference to be related to a significantly higher rate of pneumothorax in the subclavian puncture group.

Parsonnet et $a l^{3}$ found that complication rates rose significantly with increasing numbers of physicians and with the participation of inexperienced surgeons. In our series no significant difference in complication rates were identified between experienced and inexperienced operators. Inexperienced operators in our series were defined as physicians implanting 25 to 75 pacemakers during their training, which was somewhat more than the Parsonnet et al study (12 or fewer annually). ${ }^{3}$

A low incidence of pacemaker infections was seen. Our finding of $0.6 \%$ was similar or lower than earlier reported. ${ }^{3416}$ All patients in our series received prophylactic antibiotics.

To reduce complication rates our results from January 1992-June 1994 led to the following measures: screw-in leads were first choice for atrial pacing, and cephalic vein cut down was encouraged.

After implementation the results from January 1995-October 1995 indicated a significant reduction $(629 \%)$ of atrial lead displacement; $90 \%$ of atrial leads used during this period were screw-in leads. A potential disadvantage of screw-in leads is the risk of atrial wall perforation; none was seen in our series. During the follow up period a rise in cephalic cut down was recorded and the pneumothorax rate was low. There was no significant difference in the complication rates between subclavian puncture and cephalic cut down.

After implementation the total complication rate for physiological pacing was not higher than for single chamber ventricular pacing. The overall complication rate was significantly reduced in the follow up group from 1995 compared with that from the January 1992-June 1994. The set standards for complication rates were all met during January 1995-October 1995.

\section{Conclusion}

At Odense University Hospital a better compliance with international pacing guidelines was obtained by registration of reasons for deviations followed by corrections of procedures. This was accomplished with minimal increase of costs of pacing hardware and without additional costs of procedures or of follow up. Early complications of physiological pacing were reduced by using atrial screw-in leads and by using cephalic cut down as the preferred method of venous access. After implementation of corrections all the set standards were met.

1 Recommendations for pacemaker prescription for symptomatic bradycardia. Report of a working party of the
British Pacing and Electrophysiology Group. Br Heart $f$ 1991;66:185-91.

2 Bernstein AD, Parsonnet V. Survey of cardiac pacing in the United States in 1989. Am f Cardiol 1992;69:331-8.

3 Parsonnet V, Bernstein AD, Lindsay B. Pacemakerimplantation complication rates: an analysis of some contributing factors. $\mathcal{F}$ Am Coll Cardiol 1989;13:917-21.

4 Mueller X, Sadeghi H, Kappenberger L. Complications after single versus dual chamber pacemaker implantation PACE 1990;13:711-4.

5 Andersen HR, Thuesen L, Bagger JP, Vesterlund T, Thomsen PE. Prospective randomised trial of atrial versus ventricular pacing in sick sinus syndrome. Lancet 1994;344:1523-8.

6 Rosenqvist M, Brandt J, Schüller H. Longterm pacing in sinus node disease: effects of stimulation mode on cardiovascular morbidity and mortality. Am Heart $\mathcal{F} 1988$; 116:16-22.

7 Sulke N, Dritsas A, Bostock J, Wells A, Morris R, Sowton E. "Subclinical" pacemaker syndrome: a randomised study of symptom free patients with ventricular demand (VVI) pacemakers upgraded to dual chamber devices. Br Heart $\mathcal{f}$ pacemakers upg

8 Ray SG, Griffith MJ, Jamieson S, Bexton RS, Gold RG Impact of the recommendations of the British Pacing and Electrophysiology Group on pacemaker prescription and on the immediate costs of pacing in the Northern Region. $B r$ Heart 7 1992;68:531-4

9 Linde-Edelstam C, Gullberg B, Norlander R, Pehrsson $S K$, Rosenquist M, Ryden L. Longevity in patients with high degree atrioventricular block paced in the atrial synchronous or the fixed rate ventricular inhibited mode. $P A C E$ 1992;15:304-13.

10 Nathan AW, Davies DW. Is VVI pacing outmoded? $\mathrm{Br}$ Heart $\mathcal{f} 1992 ; 67: 285-8$

11 de Belder MA, Linker NJ, Jones S, Camm AJ, Ward DE. Cost implications of the British Pacing and Electrophysiology Group's recommendations for pacing. $B M \mathcal{F}$ 1992;305:861-5.

12 Mounsey JP, Ray SG, Griffith MJ, Gold RG, Bexton RS Impact of internal audit on pacemaker prescription and the immediate costs of pacing in the Northern Region: towards implementations of the recommendations of the British Pacing and Electrophysiology Group. Br Heart $\mathcal{f}$ 1994;71:395-8.

13 Chauhan A, Grace AA, Newell SA, Stone DL, Shapiro LM, Schofield PM, et al. Early complications after dua chamber versus single chamber pacemaker implantation. PACE 1994;17:2012-5.

14 Sutton R, Bourgeois I. Cost benefit analysis of single and dual chamber pacing for sick sinus syndrome and atrioventricular block. Eur Heart $\mathcal{f}$ 1996;17:574-82.

15 Parsonnet V, Furman S, Smyth NP. Implantable cardiac pacemakers status report and resource guideline. Pacemaker Study Group. Circulation 1974;50:21-35.

16 Aggarwal RK, Connelly DT, Ray SG, Ball J, Charles RG. Early complications of permanent pacemaker implantations: no difference between dual and single chamber systems. Br Heart f 1995;73:571-5.

17 Markewitz A, Wenke K, Weinhold C. Reliability of atrial screw-in leads. $P A C E$ 1988;11:1777-83.

18 Furman $S$. Venous cutdown for pacemaker implantation. Ann Thorac Surg 1986;41:438-9. 